\title{
The effect of different frequencies of electroacupuncture on BDNF and NGF expression in the hippocampal CA3 area of the ischemic hemisphere in cerebral ischemic rats
}

This article was published in the following Dove Press journal:

Neuropsychiatric Disease and Treatment

\author{
Xiaodong Duan' \\ Lei Zhang ${ }^{2}$ \\ Jihua $\mathrm{Yu}^{\prime}$ \\ Wei $\mathrm{Wei}^{3}$ \\ Xi Liu' \\ Fangyuan $\mathrm{Xu}{ }^{\prime}$ \\ Shengmin Guo' \\ 'Department of Rehabilitation \\ Medicine, Affiliated Hospital of \\ Southwest Medical University, Luzhou, \\ Sichuan 646000, China; ${ }^{2}$ School of \\ Public Health, Southwest Medical \\ University, Luzhou, Sichuan 646000, \\ China; ${ }^{3}$ Department of Neurology, \\ Affiliated Hospital of Southwest \\ Medical University, Luzhou, Sichuan \\ 646000 , China
}

\begin{abstract}
Objective: The aim of this study was to observe the effects of different frequencies of electroacupuncture (EA) on expression of brain-derived neurotrophic factor (BDNF) and nerve growth factor (NGF) in the hippocampal CA3 region of cerebral ischemic rats.

Methods: Middle cerebral artery occlusion was successfully introduced to simulate cerebral infarction in 48 healthy male Sprague-Dawley rats. Totally, 48 rats were randomly divided into three groups: the control group, the EA 5-Hz group, and the EA 50-Hz group, 16 in each group. The rats in the control group were placed in an ordinary cage and fed normally without any treatment. EA treatment was given at a certain frequency 24 hours after surgery in the EA $5-\mathrm{Hz}$ group and EA 50-Hz group. Morris water maze test was used to measure the learning and memory abilities of rats in each group after 14-day treatment with EA. Immunohistochemical staining was used to detect the expression of BDNF- and NGF-positive cells in the ischemic hippocampal CA3 area of the rats.
\end{abstract}

Results: The EA 5-Hz group and EA 50-Hz group had significantly improved learning and memory ability compared with the control group according to Morris water maze findings $(P<0.05)$. The number of BDNF- and NGF-positive cells in the hippocampal CA3 region of the ischemic hemisphere in the 5-Hz group and 50-Hz EA group was significantly more than that in the control group after EA treatment $(P<0.05)$, and the difference in the 50-Hz group was more obvious than that in the $5-\mathrm{Hz}$ group. The difference was statistically significant $(P<0.05)$.

Conclusion: EA stimulation of "Baihui" and "Dazhui" can promote the expression of BDNF and NGF in the hippocampal CA3 region of cerebral ischemic rats, and the 50-Hz EA stimulation effect is more obvious.

Keywords: cerebral infarction, electroacupuncture, brain-derived neurotrophic factor, nerve growth factor

\section{Introduction}

Stroke is considered as one of the leading causes of long-term disability around the world. ${ }^{1}$ Learning and memory dysfunction is a common complication in stroke patients, which not only greatly affects their rehabilitation and quality of life but also imposes a tremendous burden on their families and society. Acupuncture is one of the most commonly used and important therapies in traditional Chinese medicine and has been applied clinically for over a millennium. ${ }^{2}$ Electroacupuncture (EA) is a combination of electrical stimulation with acupuncture, which has been widely used
Shengmin Guo

Department of Rehabilitation Medicine, Affiliated Hospital of Southwest Medical University, No 25 Taiping Street, Jiangyang District, Luzhou 646000

Sichuan, China

Tel +868323165673; +86832316 5671

Email x5।44@।63.com;

2930773281@qq.com 
to treat stroke patients. Baihui (GV20) and Dazhui (GV14), which belong to the governor meridian, are two important acupoints for improving intelligence. Acupuncture on the two acupoints can help promote the circulation of blood, regain consciousness, and keep the balance of Yin and Yang. ${ }^{3}$ Previous studies have found that EA Baihui and Dazhui can improve cerebral neurological function as well as learning and memory. ${ }^{4,5}$ However, the mechanism for this improvement remains unclear.

We speculate a mechanism by which learning and memory improvement may be related to the expression of brain-derived neurotrophic factor (BDNF) and nerve growth factor (NGF). ${ }^{67} \mathrm{BDNF}$ is a basic protein molecule that is mainly distributed in the hippocampus and cortex in the brain, as well as in the striatum, the superior colliculus, and peripheral nerves. It is essential for developmental events of the nervous system, including proliferation, migration, differentiation, survival, apoptosis, and synaptic plasticity. ${ }^{8}$ Owing to its well-established role in synaptic plasticity and its neurotrophic ability to induce changes in synaptic morphology, BDNF has become an attractive candidate as a molecular mediator of learning and memory. ${ }^{9}$ NGF is mainly synthesized by nerve cells and astrocytes. The brain regions that express high to low levels of NGF are the hippocampus, cerebral cortex, olfactory bulb, basal ganglia, forebrain, cerebellum, and striatum in sequence. ${ }^{10} \mathrm{NGF}$ is an early nerve cell growth regulator with biological functions such as nourishing neurons and promoting neurite outgrowth. It plays an important regulatory role in the development, differentiation, growth, regeneration, and expression of functional traits in central and peripheral neurons and results in enhanced memory function and other biological effects. ${ }^{11}$ Hippocampus is an important structure in which the brain participates in learning and memory processes. It is associated with learning and memory, especially spatial cognitive function, and the CA3 region of the hippocampus is believed to be particularly closely related to spatial learning and memory activities. ${ }^{12}$

Based on the above background, a rat model of right middle cerebral artery occlusion (MCAO) was developed using a modified suture method in the present study. The Baihui point and Dazhui point were stimulated by EA at different frequencies in these cerebral ischemic rats. We then investigated the effect of EA on learning and memory in rats with cerebral ischemia and the expression of BDNF and NGF in the hippocampal CA3 region of the ischemic side to explore the mechanism by which EA improves the learning and memory abilities of rats with cerebral ischemia.

\section{Materials and methods}

\section{Animals and experimental groups}

Forty-eight male Sprague-Dawley rats of clean grade, weighing $(200 \pm 50) \mathrm{g}$ and aged 8 weeks, were provided by the Experimental Center of Southwest Medical University. The rats were housed five per cage in a temperature-controlled room $\left(20^{\circ} \mathrm{C}-30^{\circ} \mathrm{C}\right)$ on a $12 / 12$-hour light/dark cycle with access to food and water ad libitum. Rats were fed for 1 week and allowed to adapt to vivarium conditions. They were randomly and evenly divided into three groups as follows: 1) the control group, 2) the EA 5-Hz group, and 3) the EA $50-\mathrm{Hz}$ group, with 16 rats in each group. All experimental procedures were conducted in accordance with the Guidance Suggestions for the Care and Use of Laboratory Animals, issued by the Ministry of Science and Technology of China. Ethical approval was given by the Medical Ethics Committee of the Southwest Medical University (No 20170111001).

\section{Establishment of the middle cerebral artery ischemia model}

Rat models of right MCAO were established using the suture occlusion method according to established methods of the middle cerebral artery ischemia model developed by Longa et al and Chen et al. ${ }^{13,14}$ With room temperature maintained at $20^{\circ} \mathrm{C}-30^{\circ} \mathrm{C}$, the rats were immobilized on the operating table under intraperitoneal anesthesia (1\% pentobarbital sodium, $30-40 \mathrm{mg} / \mathrm{kg}$ ). Following sterilization, the right common carotid artery, internal carotid artery, external carotid artery, and pterygopalatine artery were carefully isolated through a median neck incision. The internal carotid artery was dissected and reserved, and then encircled with a suture at the start of the pterygopalatine artery. The external carotid artery and the proximal end of the common carotid artery were ligated, and then a $0.2-\mathrm{mm}$ diameter incision was made at the bifurcation of the common carotid artery $\sim 5 \mathrm{~mm}$ proximal to the end. A nylon fishing line presoaked with polylysine was inserted into the common carotid artery incision and then into the skull along the internal carotid artery after it walked through the carotid artery bifurcation; insertion of the line was stopped upon reaching the anterior cerebral artery, and a slight resistance was felt. The insertion depth was $17-19 \mathrm{~mm}$ from the bifurcation of the common carotid artery, which was ligated using sutures. Then, the internal carotid artery was tied with a surgical wire to tighten the line, the excess nylon thread was cut, and the skin was sutured. Successful model establishment was confirmed as follows: after the rats woke up, 1) adduction-flexion deformity was observed in the left limbs when the tails 
were lifted; 2) Horner's sign developed in the ipsilateral limb; 3) rats circled to the left when crawling; and 4) rats leaned to the left when standing. Rats possessing at least one of the above symptoms were included in this study. Animals that died during the experimental period were replaced to ensure an appropriate number of animals in each group. After the operation, the rats were placed in a feeding box filled with clean bedding, free access to food and water, and a dropper that could be used when necessary.

\section{EA treatment}

EA at the corresponding frequency commenced 24 hours after the operation in rats in the $5-\mathrm{Hz}$ and $50-\mathrm{Hz}$ EA groups, while the control group was only given normal diet but no EA intervention. The specifications of the EA performed in this study were as follows. 1) Acupoint selection: the "Baihui" acupoint and "Dazhui" acupoint are acupoints commonly used in rats (as defined in the reference book "Experimental Acupuncture Science"). The acupoint "Baihui" in MCAO rats is located at the right midpoint of the parietal bone, and "Dazhui" is located in the middle of the back between the seventh cervical vertebrae and the first thoracic vertebrae. 2) Acupuncture therapy: a sterilized stainless-steel needle (1 inch in length, No 28; Huatuo manufacturer, Luoyang, China) was inserted obliquely into the "Baihui" acupoint at an angle of $15^{\circ}-45^{\circ}$ and inserted directly into the "Dazhui" acupoint, at a depth of 0.5 inch at each acupoint (Figure 1). The needles were connected to the output terminals of an EA apparatus (Xinsheng Industrial Co, Ltd, Qingdao, China). Electrical stimulation parameters were set at a frequency of $5 \mathrm{~Hz}$ in the $5-\mathrm{Hz}$ EA group and $50 \mathrm{~Hz}$ in the $50-\mathrm{Hz}$ EA group. Continuous waves with a pulse width of $0.6 \mathrm{~ms}$ were delivered in both groups at intensities of 1-2 mA and voltages of $1.5-3.0 \mathrm{~V}$. The intensity was maintained at a level that was tolerable by the rats and the voltage was kept just below the level that induced visible muscle contraction. The needles were left in place for 15 minutes. Acupuncture therapy was given in the afternoon once per day for 14 successive days.

\section{Morris water maze test}

All three groups of rats were subjected to the Morris water maze test, including orientation navigation and space exploration trials following EA treatment. This test was conducted to investigate spatial learning and memory ability. The Morris water maze video tracking and analysis system (S1000; Taimeng Technology Co, Ltd, Chengdu, China) comprises a stainless-steel circular water tank (diameter, $120 \mathrm{~cm}$; height, $55 \mathrm{~cm}$ ) equipped with a platform (diameter, $10 \mathrm{~cm}$; height, $21 \mathrm{~cm}$ ) placed in the third quadrant and submerged $1 \mathrm{~cm}$ below the surface of the water. A video camera attached to a computer was placed above the center of the tank to record and analyze the trajectory of the rats. During the orientation navigation trials, each rat was placed in the water at each of four locations equidistant to the platform in clockwise order, from quadrant I, quadrant II, quadrant III to quadrant IV in sequence. The computer recorded the length of the route and the time it took the rat to find the platform. The time spent searching for the platform within 2 minutes was recorded as the escape latency. When a rat arrived at the platform within the 2-minute time restriction, the rat was considered to have found the platform and the escape latency was recorded. If the rat failed to find the platform within 2 minutes, it was removed from the water and placed on the platform for 10 seconds, and the escape latency was recorded as 2 minutes. The orientation navigation trials were repeated once per day for 5 days. The space exploration test was performed to assess
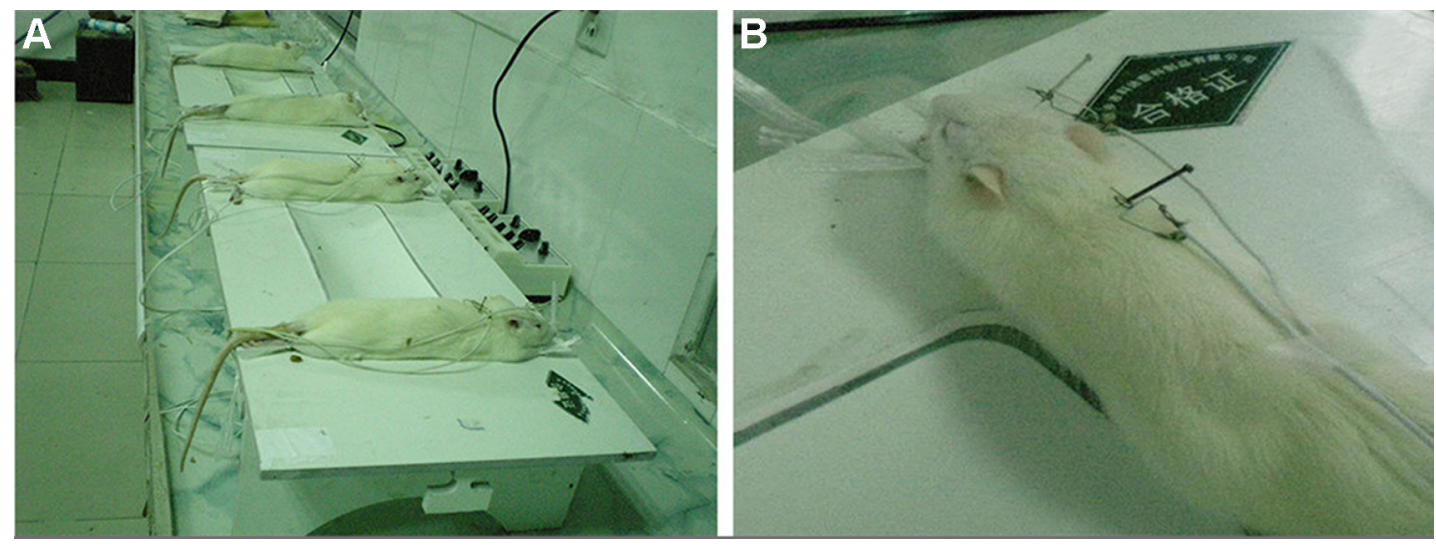

Figure I Rats of MCAO model were treated with EA at the "Baihui" acupoint and "Dazhui" acupoint.

Notes: (A) Rats under EA treatment. (B) The front needle position is at the "Baihui" acupoint, and the other is at the "Dazhui" acupoint. Abbreviations: MCAO, middle cerebral artery occlusion; EA, electroacupuncture. 
memory consolidation the day following the completion of the orientation navigation trials. In this trial, the platform was removed from the tank, and the rats were placed in the water at the same location in quadrant $I$ as in the orientation navigation trials. The rats were allowed to swim freely for 2 minutes. The number of times that each rat crossed the same location of the original platform, the swimming time and paths in each quadrant, and the total swimming path etc were recorded. Then, the ratio of the swimming distance in the original platform quadrant (quadrant III) to the total swimming distance $(\mathrm{dP} / \mathrm{dT})$ and the swimming time in the original platform quadrant to the total swimming time (tP/tT) were calculated.

\section{Sample preparation}

Samples were prepared after the Morris water maze test. The rats were anesthetized with $1 \%$ pentobarbital sodium via peritoneal injection following immobilization on a clean bench. The chest was opened quickly, and the rat was rapidly perfused with $250 \mathrm{~mL}$ saline until the effluent from the left ventricle became clear, followed by a slow infusion of 4\% paraformaldehyde in PBS (200 mL) for 15-30 minutes. Subsequently, the brain was removed, and the hippocampus was harvested, fixed in 4\% paraformaldehyde for 4-6 hours, and then moved to an alcohol gradient. The hippocampal CA3 region was dissected according to "The Rat Brain in Stereotaxic Coordinates." 31 The tissue samples obtained were fixed in 3\% glutaraldehyde and 4\% paraformaldehyde.

\section{Immunohistochemical detection of BDNF and NGF expression}

The brain tissue was embedded in paraffin, serially sectioned coronally at a thickness of $5 \mu \mathrm{m}$ using an ultramicrotome, and dried. The paraffin sections were dewaxed to water, pretreated with $\mathrm{H}_{2} \mathrm{O}_{2}(3 \%)$ to quench endogenous peroxidase activity in the tissue for 5-10 minutes at room temperature, and then washed with distilled water three times for 5 minutes each.
Then, antigen retrieval was performed as follows: sections were rinsed three times with $0.1 \mathrm{~mol} / \mathrm{L}$ PBS $(\mathrm{pH} 7.2)$ for 5 minutes each and placed in $3 \% \mathrm{H}_{2} \mathrm{O}_{2}$ methanol solution at room temperature for 5-10 minutes. After three washes with distilled water for 5 minutes each, endogenous peroxidase was blocked. The sections were immersed in $0.15 \mathrm{~mol} / \mathrm{L}$ $\mathrm{NaCl}$ buffer solution (Tris-buffered saline, $\mathrm{pH}$ 7.6), placed on a metal frame, and pressurized slowly in a pressure cooker. The sections were then removed from the heat after 10 minutes and rinsed in PBS three times after they cooled to room temperature. Antigen retrieval solution was added dropwise to the sections for 8 minutes at room temperature, and the sections were rinsed three times in PBS. The sections were incubated with anti-BDNF and anti-NGF primary antibodies (ab205067, ab6199; Abcam, Cambridge, UK) for 1 hour at $37^{\circ} \mathrm{C}$ in a water bath, rinsed with PBS three times for 5 minutes per wash and incubated for 20 minutes at $37^{\circ} \mathrm{C}$ in a water bath following the addition of EnVision reagent (DAKO, Denmark). Then, the sections were rinsed with PBS three times for 5 minutes per wash. Subsequently, the sections were developed with 3,3'-diaminobenzidine for 5-20 minutes as follows: $1 \mathrm{~mL}$ distilled water was mixed with one drop of $\mathrm{A}, \mathrm{B}$, and $\mathrm{C}$ solution, sequentially, and then the mixture was added to the sections. The sections were developed at room temperature for 12-15 minutes under a microscope. Finally, distilled water was used to terminate the coloration. One section randomly chosen from each group was counterstained with hematoxylin, followed by dehydration, clearing, mounting, microscopic observation, and image collection using a digital camera. Immunohistochemical staining and expression of BDNF and NGF in each group were observed in a visual field at $400 \times$ magnification under a light microscope (Olympus Corporation, Tokyo, Japan), and positively stained cells in the field were counted and averaged to obtain the mean values using Image Pro Plus 6.0 software (Media Cybernetics, Rockville, MD, USA). The detailed experimental procedure is summarized in Table 1.

Table I Summary of detailed experimental schedule

\begin{tabular}{|c|c|c|c|c|c|c|c|}
\hline Day/group & DI-7 & D8 & D9-23 & D24-29 & D30 & D3 I & D32-40 \\
\hline $\begin{array}{l}\text { Control } \\
\text { group }\end{array}$ & $\begin{array}{l}\text { Feeding and } \\
\text { adapting to the } \\
\text { environment }\end{array}$ & $\begin{array}{l}\text { Making } \\
\text { MCAO model }\end{array}$ & $\begin{array}{l}\text { Normal } \\
\text { feeding }\end{array}$ & $\begin{array}{l}\text { Orientation } \\
\text { navigation } \\
\text { experiment }\end{array}$ & $\begin{array}{l}\text { Space } \\
\text { exploration } \\
\text { experiment }\end{array}$ & $\begin{array}{l}\text { Brain tissue } \\
\text { fixation }\end{array}$ & $\begin{array}{l}\text { Immunohistochemistry } \\
\text { (BDNF and NGF) }\end{array}$ \\
\hline $\begin{array}{l}5-\mathrm{Hz} \text { EA } \\
\text { group }\end{array}$ & $\begin{array}{l}\text { Feeding and } \\
\text { adapting to the } \\
\text { environment }\end{array}$ & $\begin{array}{l}\text { Making } \\
\text { MCAO model }\end{array}$ & $\begin{array}{l}\text { Start } 5-\mathrm{Hz} \\
\text { EA therapy } \\
\text { I/day }\end{array}$ & $\begin{array}{l}\text { Orientation } \\
\text { navigation } \\
\text { experiment }\end{array}$ & $\begin{array}{l}\text { Space } \\
\text { exploration } \\
\text { experiment }\end{array}$ & $\begin{array}{l}\text { Brain tissue } \\
\text { fixation }\end{array}$ & $\begin{array}{l}\text { Immunohistochemistry } \\
\text { (BDNF and NGF) }\end{array}$ \\
\hline $\begin{array}{l}50-\mathrm{Hz} \mathrm{EA} \\
\text { group }\end{array}$ & $\begin{array}{l}\text { Feeding and } \\
\text { adapting to the } \\
\text { environment }\end{array}$ & $\begin{array}{l}\text { Making } \\
\text { MCAO model }\end{array}$ & $\begin{array}{l}\text { Start } 50-\mathrm{Hz} \\
\text { EA therapy } \\
\text { I/day }\end{array}$ & $\begin{array}{l}\text { Orientation } \\
\text { navigation } \\
\text { experiment }\end{array}$ & $\begin{array}{l}\text { Space } \\
\text { exploration } \\
\text { experiment }\end{array}$ & $\begin{array}{l}\text { Brain tissue } \\
\text { fixation }\end{array}$ & $\begin{array}{l}\text { Immunohistochemistry } \\
\text { (BDNF and NGF) }\end{array}$ \\
\hline
\end{tabular}

Abbreviations: MCAO, middle cerebral artery occlusion; EA, electroacupuncture; BDNF, brain-derived neurotrophic factor; NGF, nerve growth factor. 


\section{Statistical analysis}

Data were analyzed using the SPSS package, version 18.0 (SPSS Inc, Chicago, IL, USA), and the results were expressed as mean $\pm \mathrm{SD}$. Differences among groups were compared using one-way ANOVA. The least significant difference was used for pairwise comparison between groups and homogeneity of variance test and $t$-test for comparison within the group. The differences were considered statistically significant when the two-tailed $P$-values were $<0.05$.

\section{Results}

\section{Learning and memory ability assessment}

In the orientation navigation test, the $5-\mathrm{Hz}$ and $50-\mathrm{Hz}$ EA group rats exhibited significantly shorter escape latencies and total swimming path lengths than the control group $(P<0.05)$. Furthermore, the 50-Hz EA group rats demonstrated significantly shorter escape latencies than the 5-Hz EA group rats $(P<0.05$, Table 2$)$. In the space exploration test, the rats in the $5-\mathrm{Hz}$ and $50-\mathrm{Hz}$ EA groups passed through the original position of the platform significantly more number of times and exhibited significantly higher $\mathrm{tP} / \mathrm{tT}$ and $\mathrm{dP} / \mathrm{dT}$ than those in the control group $(P<0.05)$. Meanwhile, the rats in the $50-\mathrm{Hz}$ EA group rats crossed the position of the platform significantly more number of times than those in the $5-\mathrm{Hz}$ EA group $(P<0.05)$; however, there was no significant difference in the $\mathrm{tP} / \mathrm{tT}$ or $\mathrm{dP} / \mathrm{dT}$ between the two EA groups. Collectively, the Morris water maze test results reveal that the learning and memory abilities of the $5-\mathrm{Hz}$ and $50-\mathrm{Hz}$ EA group rats were better than those in the control group rats, suggesting that EA improves the learning and memory abilities of MCAO rats.

\section{Expression of BDNF-positive cells in the hippocampal $\mathrm{CA} 3$ region in the ischemic hemispheres of MCAO rats in each group}

Under light microscopy, we observed a brownish yellow immunohistochemical reaction product of BDNF in the cytoplasm. BDNF cells in the hippocampal CA3 region of the control group were weakly to moderately stained, and BDNF-positive neurons were disorderly arranged, with the cytoplasm showing a brownish yellow to light yellow color. Usually, degenerated neurons demonstrate the following changes: neuronal nucleus shrinkage, cytoplasmic contraction and deformation, and the disappearance of Nissl body. Sometimes the structure of neurons or nerve fibers becomes disorganized or disaggregated. These are "disordered neurons." In the control group, the neurons were significantly degenerated (Figure 2A), and there were significantly fewer BDNF-positive cells than in the $5-\mathrm{Hz}$ and $50-\mathrm{Hz}$ EA groups $(P<0.05)$. However, BDNF cells in the hippocampal CA3 region of the $5-\mathrm{Hz}$ and the $50-\mathrm{Hz}$ EA groups were moderately to strongly stained with brownish cytoplasm. There was no obvious neuron degeneration, but the neurons were slightly disordered (Figure $2 \mathrm{~B}$ and $\mathrm{C}$ ). The number of BDNF- and NGF-positive cells in the 50-Hz EA group was remarkably and significantly higher than that in the 5-Hz EA group and control group $(P<0.05)$, as shown in Table 3.

\section{Analysis of NGF-positive cell expression in the hippocampal CA3 region in the ischemic hemisphere of MCAO rats in each group}

Under light microscopy, the NGF protein immunohistochemical reaction substance was observed to be brownish yellow and showed cytoplasmic staining. In the control group, NGF cells in the hippocampal CA3 region showed weak to moderate expression. The control group expressed significantly fewer NGF-positive cells than the $5-\mathrm{Hz}$ and $50-\mathrm{Hz}$ EA groups $(P<0.05)$, and the cytoplasm of NGF-positive cells in the control group was brownish yellow to light yellow (Figure 3A). In the 5-Hz and 50-Hz EA groups, NGF staining in the hippocampal CA3 region showed moderate to strong expression. Positive particles were seen not only in the cytoplasm but also in cell protrusions and in some cell nuclei (Figure 3B and C). The number of NGF-positive cells

Table 2 Comparison of performance on the Morris water maze learning and memory test in each group ( $\mathrm{x} \pm \mathrm{s})$

\begin{tabular}{|c|c|c|c|c|c|c|}
\hline \multirow[t]{2}{*}{ Group } & \multirow[t]{2}{*}{ Cases } & \multicolumn{2}{|c|}{ Orientation navigation experiment } & \multicolumn{3}{|c|}{ Space exploration experiment } \\
\hline & & $\begin{array}{l}\text { Escape } \\
\text { latency (s) }\end{array}$ & $\begin{array}{l}\text { Total path } \\
\text { length }(\mathrm{cm})\end{array}$ & $\begin{array}{l}\text { Number of } \\
\text { platform } \\
\text { crossings }\end{array}$ & $\mathbf{t P} / \mathbf{t T}$ & $\mathrm{dP} / \mathrm{dT}$ \\
\hline Control group & 16 & $70.17 \pm 5.12$ & $528.04 \pm 154.34$ & $1.4 \mathrm{I} \pm 0.32$ & $0.131 \pm 0.045$ & $0.14 I \pm 0.052$ \\
\hline 5-Hz EA group & 16 & $48.42 \pm 6.5 \mathrm{I}^{\mathrm{a}, \mathrm{b}}$ & $458.32 \pm I \mid 12.32^{\mathrm{a}, \mathrm{b}}$ & $2.24 \pm 0.87^{\mathrm{a}, \mathrm{b}}$ & $0.212 \pm 0.078^{a}$ & $0.275 \pm 0.068^{\mathrm{a}}$ \\
\hline 50-Hz EA group & 16 & $44.2 \mathrm{I} \pm 5.24^{\mathrm{a}, \mathrm{b}}$ & $\left.42|.67 \pm| 33.4\right|^{\mathrm{a}, \mathrm{b}}$ & $3.12 \pm 0.58^{\mathrm{a}, \mathrm{b}}$ & $0.215 \pm 0.098^{\mathrm{a}}$ & $0.25 I \pm 0.05 I^{a}$ \\
\hline
\end{tabular}

Notes: a Compared with the control group, $P<0.05$. ${ }^{\circ}$ Compared between the $5-\mathrm{Hz}$ group and the $50-\mathrm{Hz}$ group, $P<0.05$.

Abbreviation: EA, electroacupuncture. 

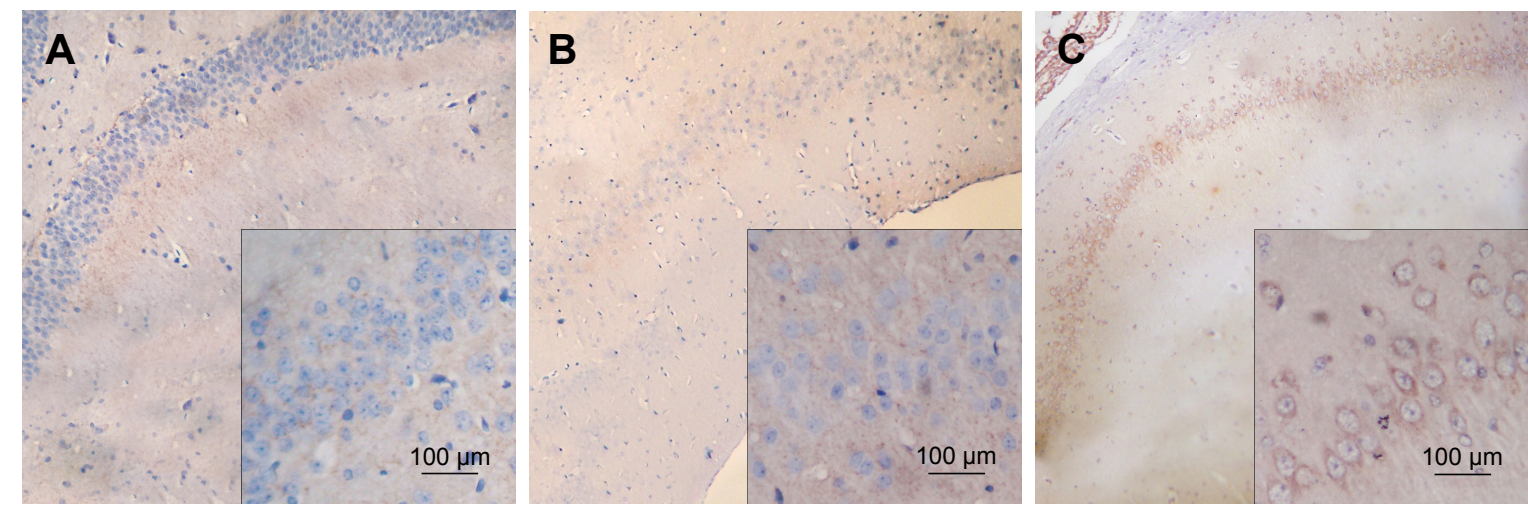

Figure 2 Expression of BDNF-positive cells in the hippocampal CA3 region in the three groups (IHC staining, 400x): (A) control group; (B) 5-Hz EA group; (C) 50-Hz EA group.

Abbreviations: EA, electroacupuncture; BDNF, brain-derived neurotrophic factor; IHC, immunohistochemistry.

in the 50-Hz EA group was significantly higher than that in the 5-Hz EA group $(P<0.05)$.

\section{Discussion}

Both BDNF and NGF are neurotrophic factors that play a crucial role in the development of the central nervous system. Experimental studies have found that BDNF and NGF can promote neuronal survival and growth and prevent apoptosis after ischemia, as well as improve neuronal pathological conditions, promote the regeneration and differentiation of damaged neurons, and play an important role in the repair of central nervous system injury. ${ }^{15,16}$ Through its participation in the protective process of cerebral ischemic injury, ${ }^{17} \mathrm{BDNF}$ can promote growth, survival, and neurogenesis of neurons; resist injury; and promote injured neuron repair after ischemia. The longer the ischemia lasts, the greater the damage and the more obviously BDNF mRNA will be expressed. The release and synthesis of BDNF, which is initiated through the trophic effects caused by the regulation of neural activity and other neurotrophic factors, are stabilized by its highaffinity receptor tropomyosin receptor kinase B (TrkB) and strengthened synapses. ${ }^{18}$ Petzold et al found that the level of

Table 3 Comparison of the expression of BDNF- and NGFpositive cells in the hippocampal CA3 region of MCAO rats in each group (number per high magnification field of view, mean \pm SD)

\begin{tabular}{|l|l|l|l|}
\hline Group & Cases (rats) & BDNF & NGF \\
\hline Control group & 16 & $11.31 \pm 3.08$ & $10.12 \pm 3.12$ \\
\hline $5-\mathrm{Hz}$ EA group & 16 & $23.58 \pm 5.45^{\mathrm{a}, \mathrm{b}}$ & $21.54 \pm 5.12^{\mathrm{a}, \mathrm{b}}$ \\
\hline $50-\mathrm{Hz}$ EA group & 16 & $29.18 \pm 6.12^{\mathrm{a}, \mathrm{b}}$ & $26.18 \pm 5.67^{\mathrm{a}, \mathrm{b}}$ \\
\hline
\end{tabular}

Notes: a ${ }^{2}$ Compared with the control group, $P<0.05$. ${ }^{b}$ Compared between the $5-\mathrm{Hz}$ group and $50-\mathrm{Hz}$ group, $P<0.05$.

Abbreviations: MCAO, middle cerebral artery occlusion; EA, electroacupuncture; BDNF, brain-derived neurotrophic factor; NGF, nerve growth factor.
BDNF protein in the hippocampus was positively correlated with academic performance through animal experiments, indicating that the expression of BDNF in the hippocampus is related to learning and memory. ${ }^{19} \mathrm{BDNF}$ is an important neurotrophin, and its receptor is tyrosine receptor kinase $\mathrm{B}$ (TrkB). BDNF-TrkB signal transduction pathway modulates synapse stability, GABAergic signaling, dendritogenesis, and neurogenesis. Improved and damaged learning and memory ability are, respectively, linked to the upregulation and downregulation of BDNF/TrkB signaling..$^{20} \mathrm{BDNF}$ regulates the expression of downstream genes, including the robust induction of polypeptide VGF. VGF is an activitydependent gene and is upregulated in the hippocampus by paradigms that reflect increased activity such as learning. ${ }^{21}$ Leal et al found that BDNF can regulate activity in synaptic plasticity-dependent forms, such as long-term potentiation. ${ }^{22}$ The continuous enhancement of excitatory synapse efficacy is the basis of learning and memory and can lead to the enhancement of neurotrophic factors in the hippocampus, thereby improving learning and memory abilities. NGF is mainly synthesized by nerve cells and astrocytes. Wong et al found that NGF can act on N-methyl-D-aspartate receptors, reduce intracellular $\mathrm{Ca}^{2+}$ overload, accelerate free radical clearance, reduce excitatory amino acid toxicity, and thus protect neurons. ${ }^{23}$ In their animal experiments, Zhang et al found that NGF can improve the spatial memory of mice by restoring neuronal cells in the hippocampus. ${ }^{24}$ Therefore, the expression of BDNF and NGF in the hippocampus is closely related to learning and memory. We also found that after EA treatment, the expression of BDNF and NGF in the 5-Hz and $50-\mathrm{Hz}$ EA groups was significantly higher than that in the control group $(P<0.05)$. The Morris water maze test showed that the learning and memory abilities of the rats in the $5-\mathrm{Hz}$ 

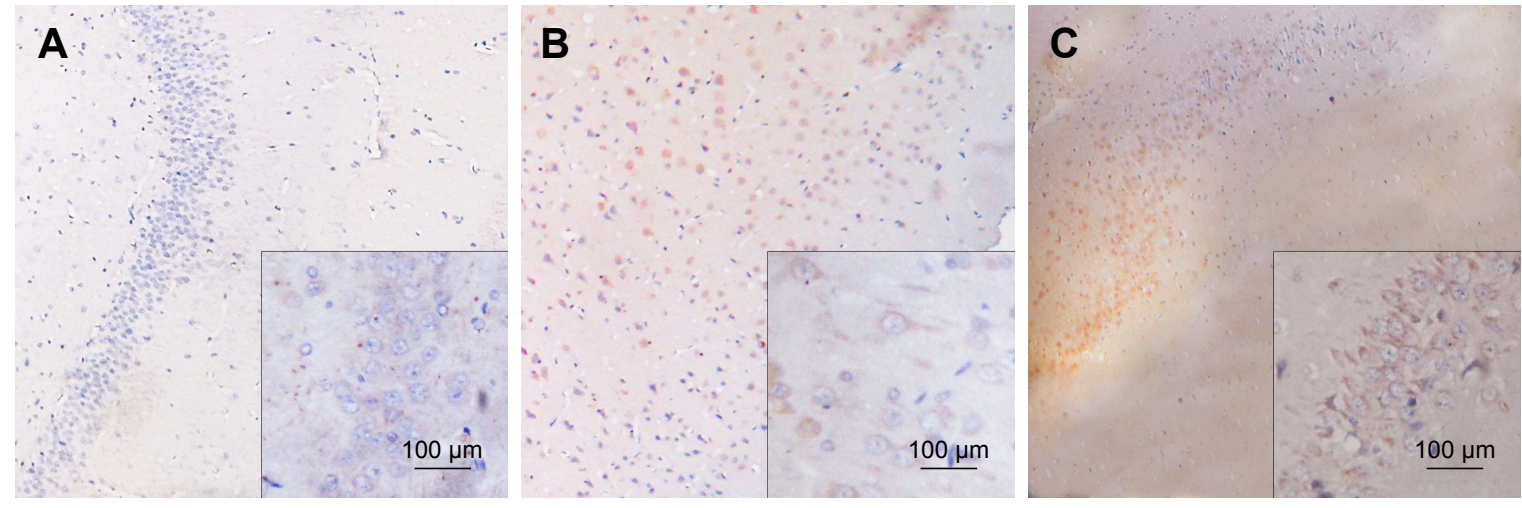

Figure 3 Expression of NGF-positive cells in the hippocampal CA3 region in the three groups (IHC staining, 400x): (A) control group; (B) 5-Hz EA group; and (C) 50-Hz EA group.

Abbreviations: EA, electroacupuncture; NGF, nerve growth factor; IHC, immunohistochemistry.

and $50-\mathrm{Hz}$ EA groups were significantly better than those of the rats in the control group.

As a traditional treatment method, EA has been widely used in clinical practice. Stroke is a disease that results in injury to the brain. The Baihui acupuncture point is located at the top of the dome of the head at the junction of five meridians, the Du meridian, the foot bladder meridian, the hand Shaoyang Sankei meridian, the foot Shaoyang gallbladder meridian, and the foot Yin Yang liver meridian. The Dazhui point is close to the head and is at the intersection of the Sanyang and Du meridians. EA at the combination of these two points can revitalize the brain, activate blood circulation, prevent blood stasis, and dredge the meridians. Chavez et al summarized the basic research in recent years and found that five different mechanisms were involved in the beneficial effects of acupuncture in ischemic stroke rehabilitation: 1) promotion of nerve cell proliferation in the central nervous system, 2) cerebral blood flow regulation in the ischemic region, 3) anti-apoptosis in the ischemic area, 4) regulation of neurochemical substances, and 5) improvement of impaired long-term potentiation..$^{25}$

Numerous basic experimental studies have shown that EA can improve the learning and memory abilities of rats with cerebral ischemia. ${ }^{26-28}$ EA treatment can enhance the expression of endogenous BDNF, thereby improving the environment to enhance survival of intracerebral neurons and inhibiting hippocampal cell apoptosis. ${ }^{29}$ EA treatment can improve brain NGF availability and action, ${ }^{30}$ EA stimulation can upregulate cerebral NGF expression in cerebral ischemia rats. The effect of EA at the "Baihui" and "Dazhui" acupoints on the treatment of cognitive dysfunction after stroke has been widely recognized, but the ideal EA stimulation frequency is not yet clear. Therefore, in this study, we used different electrical frequencies to stimulate rats with cerebral ischemia and then evaluated learning and memory ability and the expression of related factors BDNF and NGF after treatment. Finally, immunohistochemistry revealed that there were significantly more BDNF- and NGF-positive cells in the $50-\mathrm{Hz}$ EA group than in the $5-\mathrm{Hz}$ group or control group.

This experiment demonstrates that 50-Hz EA stimulation on "Baihui" and "Dazhui" can better improve the learning and memory ability of rats with cerebral ischemia, which may be due to $50-\mathrm{Hz}$ EA's role in promoting positive immune expression of BDNF and NGF in the hippocampal CA3 region of cerebral ischemia rats. However, its mechanism needs further study.

EA on "Baihui" and "Dazhui" acupoints can improve the learning and memory abilities of rats with brain deficiency. In this study, EA stimulation with 5 and $50 \mathrm{~Hz}$ frequency was used to find that $50-\mathrm{Hz}$ EA stimulation is more effective than 5-Hz EA stimulation in promoting the expression of BDNF and NGF in the hippocampal CA3 region of the ischemic side, but whether the $50 \mathrm{~Hz}$ frequency is the best stimulation frequency to improve the learning and memory ability of brain-deficient rats remains to be further studied, and the mechanism needs to be further explored as well.

\section{Disclosure}

The authors report no conflicts of interest in this work.

\section{References}

1. Xiong D, Deng Y, Huang B, et al. Icariin attenuates cerebral ischemiareperfusion injury through inhibition of inflammatory response mediated by $\mathrm{NF}-\kappa \mathrm{B}, \mathrm{PPAR} \alpha$ and PPAR $\gamma$ in rats. Int Immunopharmacol. 2016; 30:157-162.

2. Wu JN. A short history of acupuncture. J Altern Complement Med. 1996;2(1):19-21.

3. Kim M, Chung Y, Jung H. Scalp electroacupuncture at the Baihui acupoint (DU 20) improves functional recovery in rats with cerbral ischemia. Neural Regen Res. 2011;6(36):2822-2828. 
4. Pan YC, Xu NG, Yi W, Shi JH, Zheng XY. [Effect of Electroacupuncture on Learning-memory Ability in Rats with Hypoxic-ischemic Encephalopathy]. Zhen Ci Yan Jiu. 2018;43(6):370-374. Chinese.

5. Kim YR, Kim HN, Ahn SM, et al. Electroacupuncture promotes poststroke functional recovery via enhancing endogenous neurogenesis in mouse focal cerebral ischemia. PLoS One. 2014;9(2):e90000.

6. Lin R, Li L, Zhang Y, et al. Electroacupuncture ameliorate learning and memory by improving $\mathrm{N}$-acetylaspartate and glutamate metabolism in APP/PS1 mice. Biol Res. 2018;51(1):21.

7. Manni L, Aloe L, Fiore M. Changes in cognition induced by social isolation in the mouse are restored by electro-acupuncture. Physiol Behav. 2009;98(5):537-542.

8. Oliveira SL, Pillat MM, Cheffer A, Lameu C, Schwindt TT, Ulrich H. Functions of neurotrophins and growth factors in neurogenesis and brain repair. Cytometry A. 2013;83(1):76-89.

9. Rattiner LM, Davis M, Ressler KJ. Brain-derived neurotrophic factor in amygdala-dependent learning. Neuroscientist. 2005;11(4):323-333.

10. Zheng P, Zhang J, Liu H, Xu X, Zhang X. Angelica injection reduces cognitive impairment during chronic cerebral hypoperfusion through brain-derived neurotrophic factor and nerve growth factor. Curr Neurovasc Res. 2008;5(1):13-20.

11. Zhou H, Sabbagh M, Wyman R, Liebsack C, Kunik ME, Najafi B. Instrumented trail-making task to differentiate persons with no cognitive impairment, amnestic mild cognitive impairment, and alzheimer disease: a proof of concept study. Gerontology. 2017;63(2):189-200.

12. Higley MJ, Sabatini BL, Wayman GA, Lee YS, Tokumitsu H. Calcium signaling in dendrites and spines: practical and functional considerations. Neuron. 2008;59(6):902-913.

13. Longa EZ, Weinstein PR, Carlson S, Cummins R. Reversible middle cerebral artery occlusion without craniectomy in rats. Stroke. 1989;20(1): $84-91$.

14. Chen X, Zhang X, Liao W, Wan Q. Effect of physical and social components of enriched environment on astrocytes proliferation in rats after cerebral ischemia/reperfusion injury. Neurochem Res. 2017;42(5):1308-1316.

15. Hernandez-Morato I, Sharma S, Pitman MJ. Changes in neurotrophic factors of adult rat laryngeal muscles during nerve regeneration. Neuroscience. 2016;333(12):44-53.

16. Lian $\mathrm{D}, \mathrm{He} \mathrm{D}, \mathrm{Wu}$ J, et al. Exogenous BDNF increases neurogenesis in the hippocampus in experimental Streptococcus pneumoniae meningitis. J Neuroimmunol. 2016;294(294):46-55.

17. Smith PA, Peter A. BDNF: no gain without pain? Neuroscience. 2014; 283(26):107-123

18. Castrén E, Antila H. Neuronal plasticity and neurotrophic factors in drug responses. Mol Psychiatry. 2017;22(8):1085-1095.
19. Petzold A, Psotta L, Brigadski T, Endres T, Lessmann V. Chronic BDNF deficiency leads to an age-dependent impairment in spatial learning. Neurobiol Learn Mem. 2015;120:52-60.

20. Yang Y, Gao L. Celecoxib alleviates memory deficits by downregulation of COX-2 expression and upregulation of the BDNF-TrkB signaling pathway in a diabetic rat model. $J$ Mol Neurosci. 2017;62(2): 188-198.

21. Alder J, Thakker-Varia S, Bangasser DA, et al. Brain-derived neurotrophic factor-induced gene expression reveals novel actions of VGF in hippocampal synaptic plasticity. J Neurosci. 2003;23(34): 10800-10808.

22. Leal G, Bramham CR, Duarte CB. BDNF and Hippocampal Synaptic Plasticity. Vitam Horm. 2017;104:153-195.

23. Wong H, Kang I, Dong XD, et al. NGF-induced mechanical sensitization of the masseter muscle is mediated through peripheral NMDA receptors. Neuroscience. 2014;269:232-244.

24. Zhang H, Petit GH, Gaughwin PM, et al. NGF rescues hippocampal cholinergic neuronal markers, restores neurogenesis, and improves the spatial working memory in a mouse model of Huntington's Disease. J Huntingtons Dis. 2013;2(1):69-82.

25. Chavez LM, Huang SS, Macdonald I, Lin JG, Lee YC, Chen YH. Mechanisms of acupuncture therapy in ischemic stroke rehabilitation: a literature review of basic studies. Int J Mol Sci. 2017;18(11):2270.

26. Lin R, Lin Y, Tao J, et al. Electroacupuncture ameliorates learning and memory in rats with cerebral ischemia-reperfusion injury by inhibiting oxidative stress and promoting $\mathrm{p}-\mathrm{CREB}$ expression in the hippocampus. Mol Med Rep. 2015;12(5):6807-6814.

27. Lin R, Yu K, Li X, et al. Electroacupuncture ameliorates post-stroke learning and memory through minimizing ultrastructural brain damage and inhibiting the expression of MMP- 2 and MMP-9 in cerebral ischemiareperfusion injured rats. Mol Med Rep. 2016;14(1):225-233.

28. Zhang Y, Lin R, Tao J, et al. Electroacupuncture improves cognitive ability following cerebral ischemia reperfusion injury via CaM-CaMKIVCREB signaling in the rat hippocampus. Exp Ther Med. 2016;12(2): 777-782.

29. Zhao J, Xu H, Tian Y, Hu M, Xiao H. Effect of electroacupuncture on brain-derived neurotrophic factor mRNA expression in mouse hippocampus following cerebral ischemia-reperfusion injury. $J$ Tradit Chin Med. 2013;33(2):253-257.

30. Rocco ML, Pristerà A, Pistillo L, Aloe L, Canu N, Manni L. Brain cholinergic markers and Tau phosphorylation are altered in experimental type 1 diabetes: normalization by electroacupuncture. J Alzheimers Dis. 2013;33(3):767-773.

31. Paxinos G, Watson C. The Rat Brain in Stereotaxic Coordinates. 6th Edition. San Diego: Academic Press; 2007.
Neuropsychiatric Disease and Treatment

\section{Publish your work in this journal}

Neuropsychiatric Disease and Treatment is an international, peerreviewed journal of clinical therapeutics and pharmacology focusing on concise rapid reporting of clinical or pre-clinical studies on a range of neuropsychiatric and neurological disorders. This journal is indexed on PubMed Central, the 'PsycINFO' database and CAS,

\section{Dovepress}

and is the official journal of The International Neuropsychiatric Association (INA). The manuscript management system is completely online and includes a very quick and fair peer-review system, which is all easy to use. Visit http://www.dovepress.com/testimonials.php to read real quotes from published authors. 